\title{
Book Review: Amazing rare things. The art of natural history in the age of discovery
}

\author{
by David Attenborough, Susan Owens, Martin Clayton, and \\ Rea Alexandratos. 2007. Yale University Press, New Haven, \\ Connecticut, USA. 223 pp. ISBN 978-0-12547-4 (hard cover)
}

\section{Jorge A. Santiago-Blay ${ }^{1}$}

As I was considering what book to first review for Life: The Excitement of Biology, someone gave me Amazing rare things, a tome penned by Sir David Attenborough and collaborators, published in 2007. Many would consider a book published in 2007 as "old" and unworthy of a review. However, this beautifully illustrated volume prompted me to ask the questions pertinent today, "why draw" or "why do we engage in anything we do?" For me, uncovering origins, in other words, learning history is a powerful engine. Amazingly, many icons, often considered new - and hence, sadly, good - have a long history. In a time where everything moves at an ever faster - and not always well-reflected - pace, Amazing rare things is a breath of fresh air about biological illustrations through which we can learn about many objects we still see today.

Deceptively simple, Amazing rare things begins with the description of cave paintings produced by ancient humans and posses the questions, how are plurality, movement, relative size, hierarchy, tridimensionality, and others represented in the relative flatland of a cave? The answers, which we perhaps take for granted in our languages, are not obvious and different cultures, including visual ones, offer a variety of solutions. Some of the ancient pictorial representations of living things are practical and beautiful. Groups of humans that emphasized hunting tended to depict animals - some imaginary - whereas more plant-dependent groups were fond of botanical imaging. In the European Medieval age, herbals and bestiaries described the uses of entities considered botanical and zoological, respectively, and some of those have been immortalized in cinematography (e.g. the mandrake scene in Harry Potter and The Chamber of Secrets).

During the European Renaissance, humans - mostly men - dared to use their senses to observe the natural world and begin offering naturalistic explanations to phenomena. With this new philosophy, came a greater

\footnotetext{
${ }^{1}$ York, Pennsylvania, USA. E-mail: blayjorge@gmail.com
} 
emphasis in detailed, anatomically correct illustrations (e.g. da Vinci's $A$ walking bear), which did not obliterate the expression of vivid imagination, as represented in A dragon. Beautiful color illustrations are reproduced in Amazing rare things, including $A$ fox, drawn by the Swiss naturalist and Father of Zoology, Conrad Gesner (1516-1565), after whom the African violet family (Gesneriaceae) is named. Thereafter, we see supposed variations in human anatomy from the Nuremberg Chronicle (1493) and I could not but marvel at the similarity between some of the images and "modern" cinematic blockbuster characters, such as Dobby (Harry Potter and The Chamber of Secrets) and the hobbits (Lord of the Rings). However, we should not be too fast at dismissing some authors' imagination as sometimes those are exaggerated versions of real human phenomena. Also, some of our prejudices have roots in opinions of scientists (e.g. Linnaeus' views on human variation). Contrary to Gesner, who organized his entries alphabetically, Aldrovandi looked for groups based on inferred relationships. Other examples of botanically detailed images are Besler's "Corona Imperialis Polyanthos" (currently, Fritillaria imperialis L., Liliaceae) and the feeding damage on the leaves in Marshal's, A 'Mexico munky'. I found it fun to learn about the mythology behind Amphisbaena as it made me remember the first time I encountered this vermiform reptile, known in as the "culebra de dos cabezas" (two headed snake).

Amazing rare things ends with two gorgeously illustrated chapters highlighting the works of Maria Sibylla Merian (1647-1717), the German woman who travelled - and suffered - and painted the biota of South America and by the British naturalist, Mark Catesby, after whom the American bullfrog, Lithobates catesbeianus (Shaw, 1802) (formerly known as Rana catesbeiana) was named.

Long ago, I witnessed an academic job candidate who claimed that for every scientific book in his field of expertise, mostly theoretical population genetics, he has written a book review. After he left the meeting, this colleague was mocked in absentia by some amongst a group of graduate students and postdocts. While I remained cowardly quiet, I silently admired him because he did not speak to impress us by using unintelligible lingo but, instead, he wanted to translate the technical language of his field into concepts that trained scientists and others motivated to learn could grasp readily. Eventually, he got an academic job elsewhere and I trust it has been life giving for him. In the same spirit, for doing what one thinks is right, I have written this first book review for $L E B$. 